\title{
Hyaline Fibromatosis Syndrome
}

\section{Sarath Rajendrababu Syamala ${ }^{1} \cdot$ Priya Sreenivasan ${ }^{1} \cdot$ Sankar Vaikom Hariharan ${ }^{1}$}

Received: 19 September 2020 / Accepted: 2 March 2021 / Published online: 15 March 2021

(C) Dr. K C Chaudhuri Foundation 2021

To the Editor: Hyaline fibromatosis syndrome (HFS) is a rare autosomal recessive syndrome characterized by deposition of amorphous hyaline material in skin, subcutaneous tissue, and various other organs of the body resulting in papules and nodules over skin, joint contractures, gingival hypertrophy, osteopenia, and protein losing enteropathy $[1,2]$.

A 1-y-3-mo-old girl child was brought to genetic clinic in view of joint contractures. She is the first child of a thirddegree consanguineous marriage. At $1 \mathrm{mo}$, mother noticed irritability while handling the child. By 3 mo of age, the child had difficulty in moving limbs due to development of contractures in wrist, ankle, knees, and shoulder joints. At 13 mo of age, the mother noticed reddish verrucous nodules over the nape of the neck which progressed to face and posterior aspect of trunk.

Physical examination showed patchy alopecia of scalp and verrucous, pink papulonodular lesions over face, neck, and trunk. Other manifestations included coarse facies with gum hypertrophy. A firm soft-tissue swelling was present at the mandibular region, near the midline. Flexion deformities were present at bilateral elbows, shoulders, and knees. Anthropometry showed weight between 3 rd and 15 th percentile, height between 50th and 85th percentile, weight for height $<3$ rd centile, and head circumference was normal. There was delay in gross motor and fine motor and normal social and language mile stones. All other systems and investigations were normal.

In view of peculiar phenotype, genetic study was done and it showed a pathogenic homozygous variant (c.1074delT; p.Ala359HisfsTer50) in exon 13 of the ANTXR2 gene (chromosome 4) which was previously been reported in patients affected with HFS from Brazil [3]. The index case had all these clinical features suggestive of HFS (Grade 2) [3, 4].
The couple should be offered genetic counseling and option of prenatal diagnosis in future pregnancy.

\section{Declarations}

Ethics Approval This is a single case report. Institutional ethical committee, Medical College, Trivandrum has confirmed that no ethical approval is required.

Consent to Participate Written informed consent was obtained from the parent.

Consent to Publication Parents signed the documents for publishing the information and photograph in the journal.

Conflict of Interest None.

\section{References}

1. Lindvall LE, Kormeili T, Chen E, et al. Infantile systemic hyalinosis: case report and review of the literature. J Am Acad Dermatol. 2008;58(2):303-7.

2. Dowling O, Difeo A, Ramirez MC, et al. Mutations in capillary morphogenesis gene-2 result in the allelic disorders juvenile hyaline fibromatosis and infantile systemic hyalinosis. Am J Hum Genet. 2003;73(4):957-66.

3. Denadai R, Raposo-Amaral CE, Bertola D, et al. Identification of 2 novel ANTXR2 mutations in patients with hyaline fibromatosis syndrome and proposal of a modified grading system. Am J Med Genet A. $2012 ; 158 \mathrm{~A}(4): 732-42$.

4. Dhingra M, Amladi S, Savant S, Nayak C. Juvenile hyaline fibromatosis and infantile systemic hyalinosis: divergent expressions of the same genetic defect? Indian J Dermatol Venereol Leprol. 2008;74(4):371-4.

Publisher's Note Springer Nature remains neutral with regard to jurisdictional claims in published maps and institutional affiliations.

Sankar Vaikom Hariharan

sankarvh@gmail.com

1 Department of Pediatrics, SAT Hospital Government Medical College, Thiruvananthapuram, Kerala 695011, India 